\title{
Determination of fracture toughness using the area of micro-crack tracks left in brittle materials by Vickers indentation test
}

\author{
Alireza MORADKHANI ${ }^{a,{ }^{*}}$, Hamidreza BAHARVANDI ${ }^{b}$, Mehdi TAJDARI $^{c}$, \\ Hamidreza LATIFI ${ }^{d}$, Jukka MARTIKAINEN ${ }^{d}$ \\ ${ }^{a}$ Department of Mechanical Engineering, Science and Research Branch, Islamic Azad University, \\ Hesarak, Poonak, P.O. Box 14515/775, Tehran, Iran \\ ${ }^{b}$ Department of Materials Engineering, Malek Ashtar University of Technology, Lavizan, \\ P.O. Box 15875/1774, Tehran, Iran \\ ${ }^{c}$ Department of Mechanical Engineering, Science and Research Branch, Islamic Azad University, Vahdat St., \\ Hafezieh Sq., P.O. Box 381814/6775, Arak, Iran \\ ${ }^{d}$ Department of Mechanical Engineering, Laboratory of Welding Technology, Lappeenranta University of \\ Technology, Skinnarilankatu 34, P.O. Box 20, FI-53851 Lappeenranta, Finland
}

Received: December 02, 2012; Revised: February 07, 2013; Accepted: February 16, 2013

(C)The Author(s) 2013. This article is published with open access at Springerlink.com

\begin{abstract}
In this article, a new method has been presented for the estimation of fracture toughness in brittle materials, which enjoys improved accuracy and reduced costs associated with fracture toughness testing procedure compared to similar previous methods, because a vast range of specimens with irregular cracks can be accommodated for testing. Micron-sized alumina powders containing $0.05 \mathrm{wt} \%$ magnesium oxide $(\mathrm{MgO})$ nanoparticles were mixed and also together with $2.5 \mathrm{vol} \%$, $5 \mathrm{vol} \%, 7.5 \mathrm{vol} \%, 10 \mathrm{vol} \%$, and $15 \mathrm{vol} \%$ of silicon carbide (SiC) nanopowders separately. By making and testing various types of ceramics with different mechanical properties, and considering the irregular cracks around the indented area caused by Vickers diamond indenter, a semi-empirical fracture toughness equation has been obtained.
\end{abstract}

Keywords: fracture toughness; mechanical properties; nanocomposites; indentation

\section{Introduction}

Different methods have been devised for the measurement of fracture toughness in brittle materials. Chevron notch bar (CNB) [1-3], single-edge notch beam (SENB) [2-6], single-edge V-notched beam (SEVNB), single-edge pre-cracked beam (SEPB) [4,5], edge-loaded split (ELS) $[7,8]$ and the double cantilever beam (DCB) are some of these methods, most of

\footnotetext{
* Corresponding author.

E-mail: moradkhani.a@srbiau.ac.ir
}

which have limited usage because of the difficulty in preparing the ceramic samples and high expenses associated with implementation. To solve this problem, a new method has emerged in the last few decades, which relies on the evaluation of indenter's effect left in the materials [9]. In this approach, small surface cracks with controlled size and shape are easily created by indenters such as Bercovich, Conical and Vickers $[10,11]$, which leave a series of these cracks on the specimen. By examining the morphology of these cracks, the fracture toughness of the specimen is determined [12]; less equipment and raw materials (for samples) are needed, and the speeds of sample 
preparation and testing are higher compared to other methods [13].

The idea of obtaining fracture toughness in brittle materials by evaluating the effect of indenter was first developed by Palmqvist [12]. By applying Vickers hardness-testing diamond in metal carbides, Palmqvist was able to establish a relationship between fracture process and other important parameters, such as hardness [14]. Then, many other researchers followed along and developed several relations for the estimation of this mechanical property [15-29].

In this research, a method, which increases the accuracy and reduces the costs of performing fracture toughness test based on Vickers indenter, has been investigated. Alumina, with numerous industrial applications, has been used as the main raw material together with $0.05 \mathrm{wt} \%$ of magnesium oxide $(\mathrm{MgO})$ and various amounts of silicon carbide (SiC) nanopowder, which considerably changes its mechanical properties.

\section{Review of governing equations}

Three techniques are used to obtain fracture toughness equations on the basis of Vickers indentation test. The first model is based on Palmqvist cracks with half-ellipse sub-structure; the second model is based on half-penny or median cracks; and the third model is based on curve-fitting technique. Generally, the difference between the first two models is their sub-structures. In the first (Palmqvist) model, the length of the formed cracks is only measured from the tip of the indented section [14]; whereas in the second (half-penny) model, the crack length is measured radially from the center of the indented section [15]. The third approach is based on the comparison of equation results with those of other common methods. Figure 1 shows the difference between the two major models.

In Fig.1, $l$ indicates the length from the tip of the indented section to the end of the crack; $a$ is the half-diameter of the indented section; and $c$ is the sum of $l$ and $a$. it should be noted that these amounts constitute the average of all the four cracks formed around the indented zone, meaning the values of $l$ and $c$ used in the research are the average lengths of the four radial cracks. In the most noted and referenced research [15], the $c / a$ ratio is presumed to be indicative of the type of crack system. As a general rule, it is

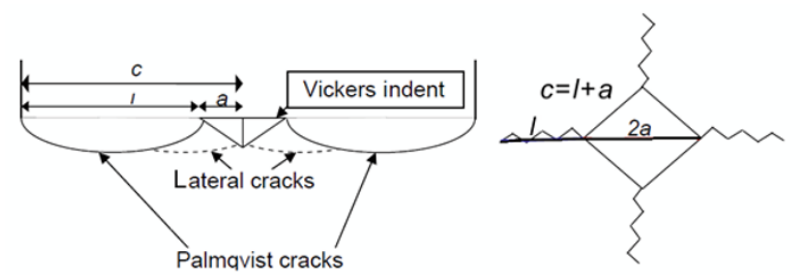

(a)

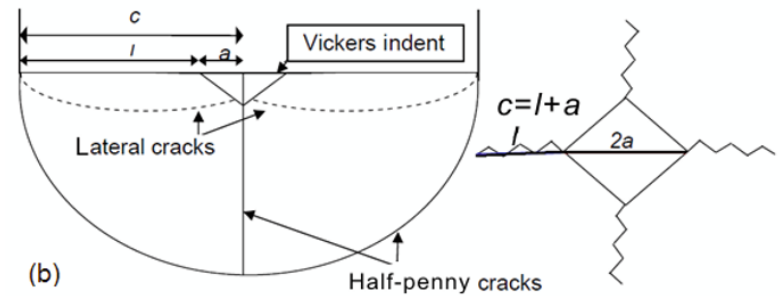

Fig. 1 (a) Palmqvist crack model; (b) half-penny crack model.

assumed that if $c / a \geqslant 2$, the crack model is considered as half-penny type, and if $c / a<2$, the crack model is considered as Palmqvist model [16,17]. In addition, the crack model may change from Palmqvist to half-penny type due to gradual and high-magnitude loadings $(\sim 90-100 g)$ [18]. Of course, there are different discussions and viewpoints about the value of this ratio and the deduced type of crack system. For example, Bhat [19] suggested that if $c / a \geqslant 3$, the crack model should be considered as half-penny, and if $c / a<3$, it should be considered as Palmqvist. In their next articles, Bamzai et al. [18] and Bhat et al. [20] also suggested that if $c / a \geqslant 2.5$, the crack model should be considered as half-penny type, and if $c / a<2.5$, it should be considered as Palmqvist. Dub and Maistrenko [21] proposed a limit value of 2.1 for this ratio to differentiate crack models.

The general and common assumption that normally governs this classification is that cracks in brittle materials with relatively low toughness are considered to follow half-penny model, and cracks with relatively high toughness can be considered to emulate Palmqvist model. Moreover, depending on the loading condition of the indenter, materials can be classified into the two mentioned models. For low-magnitude loadings, the crack model is considered as Palmqvist, and for high-magnitude loadings, the model is considered as half-penny. The exact value of this ratio depends on the brittleness of the considered materials [22].

There are many equations developed by researchers for the determination of fracture toughness based on the use of Vickers pyramid diamond indenter. All of these equations are obtained semi-empirically, meaning that the existing coefficients in these 
equations have been obtained by trial and error, and all of them emphasize the existence of crack length parameters. Some of these famous relations are listed in Table 1.

Table 1 Some equations developed for the determination of fracture toughness in brittle materials

\begin{tabular}{|c|c|c|c|}
\hline No. & Equation & Crack model & Ref. \\
\hline 1 & $K_{\mathrm{IC}}=0.016\left(\frac{E}{H_{\mathrm{V}}}\right)^{\frac{1}{2}} \frac{P}{c^{\frac{3}{2}}}$ & Half-penny & [15] \\
\hline 2 & $K_{\mathrm{IC}}=0.067 H_{\mathrm{V}} a^{\frac{1}{2}}\left(\frac{E}{H_{\mathrm{V}}}\right)^{\overline{5}}\left(\frac{c}{a}\right)^{-\frac{1}{2}}$ & Half-penny & [23] \\
\hline 3 & $K_{\mathrm{IC}}=0.0752 \frac{P}{c^{\frac{3}{2}}}$ & Half-penny & [26] \\
\hline 4 & $K_{\mathrm{IC}}=0.0726 \frac{P}{c^{\frac{3}{2}}}$ & Half-penny & [29] \\
\hline 5 & $K_{\mathrm{IC}}=0.014\left(\frac{E}{H_{\mathrm{V}}}\right)^{2} \frac{P}{c^{\frac{3}{2}}}$ & Half-penny & [28] \\
\hline 6 & $K_{\mathrm{IC}}=0.0089\left(\frac{E}{H_{\mathrm{V}}}\right)^{5}\left(\frac{P}{a c^{\frac{1}{2}}}\right)$ & Curve-fitting & [23] \\
\hline 7 & $K_{\mathrm{IC}}=0.0889\left(\frac{H_{\mathrm{V}} P}{\sum_{i=1}^{4} c_{i}}\right)^{\frac{1}{2}}$ & Curve-fitting & [24] \\
\hline 8 & $K_{\mathrm{IC}}=0.4636\left(\frac{E}{H_{\mathrm{V}}}\right)^{\overline{5}} \frac{P}{a^{\frac{3}{2}}} 10^{F}$ & Curve-fitting & [27] \\
\hline 9 & $K_{\mathrm{IC}}=0.018\left(\frac{E}{H_{\mathrm{V}}}\right)^{\frac{2}{2}} \frac{P}{c^{\frac{3}{2}}}$ & Curve-fitting & [25] \\
\hline 10 & $K_{\mathrm{IC}}=H_{\mathrm{V}} a^{\frac{1}{2}}\left(\frac{E}{H_{\mathrm{V}}}\right)^{\overline{5}} 10^{y}$ & Curve-fitting & [27] \\
\hline
\end{tabular}

In Table $1, K_{\mathrm{IC}}$ is the fracture toughness $\left(\mathrm{MPa} \cdot \mathrm{m}^{1 / 2}\right)$; $P$ is the indentation loading $(\mathrm{N}) ; c$ is the crack length $(\mathrm{mm}) ; E$ is Young's modulus $(\mathrm{GPa}) ; H_{\mathrm{V}}$ is Vickers hardness (GPa); and $a$ is the half-diameter of the sample's indented section (mm). Besides, $y$ and $F$ are obtained as

$y=-1.59-0.34 x-2.02 x^{2}+11.23 x^{3}-24.97 x^{4}+15.32 x^{5}$

$F=-1.59-0.34 x-2.02 x^{2}+11.23 x^{3}-24.97 x^{4}+16.32 x^{5}$

And the value of $x$ in the above relations is equal to

$$
x=\log \left(\frac{c}{a}\right)
$$

Although this method has attracted a lot of attention in recent years because of its simplicity and economy of implementation, it is encumbered with considerable error compared to other common fracture toughness test methods such as SEVNB, SENB and CNB. The reason for this in many cases is due to the high loading of Vickers diamond and the existing impurities in the specimen structure as well, which cause the propagation of irregular cracks around the indent. If the magnitude of loading increases, the chipping phenomenon will occur in the sample [15]. Thus, the use of the mentioned equations will lead to significant error compared to other common methods. Therefore, by controlling the amount of loading and repeating the experiment, a sample with standard radial crack can be achieved through trial and error [15]. However, the repeat of the test requires more time and imposes higher costs. Besides, one of the most important factors that lead to computational errors when using the indentation test is the disregard of secondary cracks that might have formed in the specimen around the indented zone, which cause error in the amount of fracture toughness obtained from these equations. Another cause of error in using the mentioned relations is the amount of crack propagation along the depth of the sample. The longitudinal and depthwise propagations of crack in the specimen have an inverse relationship to each other, and both affect the obtained value of fracture toughness; whereas in the expressed equations, only the longitudinal propagation of crack in the specimen is effective. The cited factors sometimes cause up to $30 \%$ error in the amount of fracture toughness, compared to common methods [15-29].

\section{Theory of the problem}

Figure 2 shows the overall schematic of crack tracks left in brittle materials by the fracture toughness test using Vickers indenter. This figure indicates that crack propagation is no longer radial, but cracks have grown

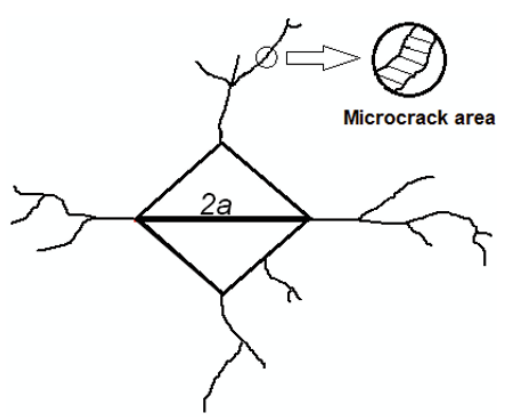

Fig. 2 A model of irregular cracks around the indented zone. 
in every direction or have branched out into smaller cracks. Since cracks may propagate haphazardly in the sample, if the area of crack tracks is used in the equations instead of crack length, it will not be necessary for cracks to be radial, provided that the area of all the formed micro-cracks is included in the fracture toughness formula.

In fact, the area of micro-cracks formed around the indented zone of the specimen can be assumed as a regular-shaped geometry. In other words, the area and thickness values of micro-cracks can be measured with software and replaced with a regular-shaped geometry, e.g., rectangular, so that the rectangular area and width are equal to the area and average thickness of the micro-crack profile, respectively. There is possibility of using micro-crack area and thickness in fracture toughness calculation. It should be noted that, the novelty of this method can provide a new path for other researches in this field. The main privilege of this simulation is that by considering thickness and area values of the assumed virtual cracks instead of real cracks, fracture toughness equation will be independent of cracks' movement path and propagation. This issue extends the range of the accepted specimens for fracture toughness measurement, and consequently, the number of tests is reduced. But, in this method, due to the low value of micro-cracks' thickness, high accuracy of measurement is required which makes the measurement process longer. Since the measurement in this method is done by software, the process of test is highly repeatable, and the results are generally accurate. It should be considered that, usually when the distance from the indented zone made by Vickers diamond indenter increases, the rate of $t$ (average thickness of the micro-crack profile) will be reduced and vice versa.

Therefore, if the profile of a micro-crack formed in the sample is considered as the general form shown in Fig. 3 and its area is assumed equal to that of a rectangle with length $c$ and thickness $t$, Eq. (2) will be obtained.

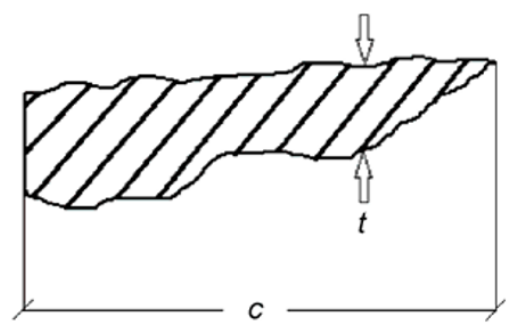

Fig. 3 General profile of micro-cracks formed in the sample.

$$
c=\frac{A}{t}
$$

In Eq. (2), $c$ is the crack length; $A$ is the micro-crack area; and $t$ is the average thickness of the micro-crack profile. Fracture toughness can also be determined through a general Eq. (3), as follows [15]:

$$
K_{\text {IC }}=\chi \frac{P}{c^{\frac{3}{2}}}
$$

where $K_{\mathrm{IC}}$ is the fracture toughness in the first fracture mode $\left(\mathrm{MPa} \cdot \mathrm{m}^{1 / 2}\right) ; P$ is the applied force $(\mathrm{N}) ; c$ is the average micro-crack length $(\mathrm{mm})$; and $\chi$ is a constant coefficient which is obtained by Eq. (4):

$$
\chi=\zeta\left(\frac{E}{H_{\mathrm{v}}}\right)^{\frac{1}{2}}
$$

In Eq. (4), the value of $\zeta$ is independent of the material. By inserting Eq. (4) into Eq. (3), a general equation (5) is obtained:

$$
K_{\mathrm{IC}}=\zeta\left(\frac{E}{H_{\mathrm{V}}}\right)^{\frac{1}{2}} \frac{P}{c^{\frac{3}{2}}}
$$

where $H_{\mathrm{V}}, E, P, c$, and $K_{\mathrm{IC}}$ respectively denote Vickers hardness of the specimen $(\mathrm{GPa})$, the modulus of elasticity $(\mathrm{GPa})$, Vickers diamond loading $(\mathrm{N})$, the average length of radial cracks in the specimen $(\mathrm{mm})$, and the fracture toughness or the critical value of stress intensity factor in the first fracture mode $\left(\mathrm{MPa} \cdot \mathrm{m}^{1 / 2}\right)$. $\zeta$ denotes a dimensionless empirical constant coefficient, which is obtained via other common methods of fracture toughness test. Anstis et al. [15] experimentally determined the value of $\zeta$ equal to $0.016 \pm 0.004$. By combining Eqs. (2) and (5), Eq. (6) is obtained:

$$
K_{\mathrm{IC}}=\zeta\left(\frac{E}{H_{\mathrm{V}}}\right)^{\frac{1}{2}} t^{\frac{3}{2}} \frac{P}{A^{\frac{3}{2}}}
$$

In Eq. (6), $t$ and $A$ represent the average thickness of all the formed micro-cracks around the indented section of the sample $(\mathrm{mm})$, and the total area of micro-crack tracks around the indented zone $\left(\mathrm{mm}^{2}\right)$, respectively.

To obtain the constant value of $\zeta$, Eq. (6) is rewritten as

$$
\zeta=K_{\mathrm{IC}}\left(\frac{H_{\mathrm{V}}}{E}\right)^{\frac{1}{2}} \frac{A^{\frac{3}{2}}}{P t^{\frac{3}{2}}}
$$

The fracture toughness of the specimen is 
determined through other common methods; the average area and thickness of the crack tracks are obtained by means of Image Analyzer Software; the hardness value of the sample is calculated by Vickers method using ASTM C1327-08 standard [30]; the magnitude of loading is also determined. The modulus of elasticity of the nanocomposite sample is determined using ASTM C769-98 standard [31], based on the speed of sound change in the sample material. Three pieces of the sample with dimensions of $2.5 \mathrm{~cm} \times 2.5 \mathrm{~cm}$ are prepared and their surfaces are polished with diamond paste up to $1 \mu \mathrm{m}$ grain size. Then ultrasonic pulse with a frequency of $4 \mathrm{MHz}$ is generated by an electrical energy converter device and emitted onto the sample surface, and the data received in return are inserted into Eq. (7). By having all the values at the right hand side of Eq. (7), the value of $\zeta$ is obtained with a tolerance for all the examined ceramics having different volume percentages of SiC. Finally, when the $\zeta$ value is known, the fracture toughness of the ceramic will be determined by Eq. (6). In the following, Image Analyzer Software and its way of calculation are described.

Image Analyzing Software with various capabilities can be freely downloaded from National Institutes of Health. This software can be used to analyze digital images by area measurement, length/size distribution, mean particle diameter, particle counts, etc. The process of image analyzing consists of two steps. First, those features of the specimen required to be analyzed should be defined so that the computer can recognize which data in the image is significant. Second, a binary image should be created based on some cut of value for pixel intensity.

In cases where the images of surface are clear to be recognized, it can be relatively straightforward to distinguish them based on pixel value alone. Sometimes, especially when there is contact between objects making it not easy to distinguish one object from others, simple thresholding is not enough to define those features one wishes to count. Adapting the contrast of the image may help the operator recognize the object of interest, but this is not the same for computer. The operator can use a marking tool to recognize the object of interest.

As an example, Figs. 4(a) and 5(a) respectively show the enlarged areas of the formed cracks in $\mathrm{Al}_{2} \mathrm{O}_{3}-7.5 \% \mathrm{SiC}$ (in volume fraction, similarly hereinafter) and $\mathrm{Al}_{2} \mathrm{O}_{3}-15 \% \mathrm{SiC}$ specimens, while in Figs. 4(b) and 5(b), software recognized the cracks from the other parts in order to measure the area and thickness values of the images.

The image analysis output can be exported as a file that can be uploaded into a spreadsheet program, such as Excel, and then analyzed. Data placed in a spreadsheet can be analyzed in various ways, containing size distribution, average size, percent area, etc.

In Figs. 6 and 7, the software is analyzing and measuring the images and the area values of cracks, respectively.

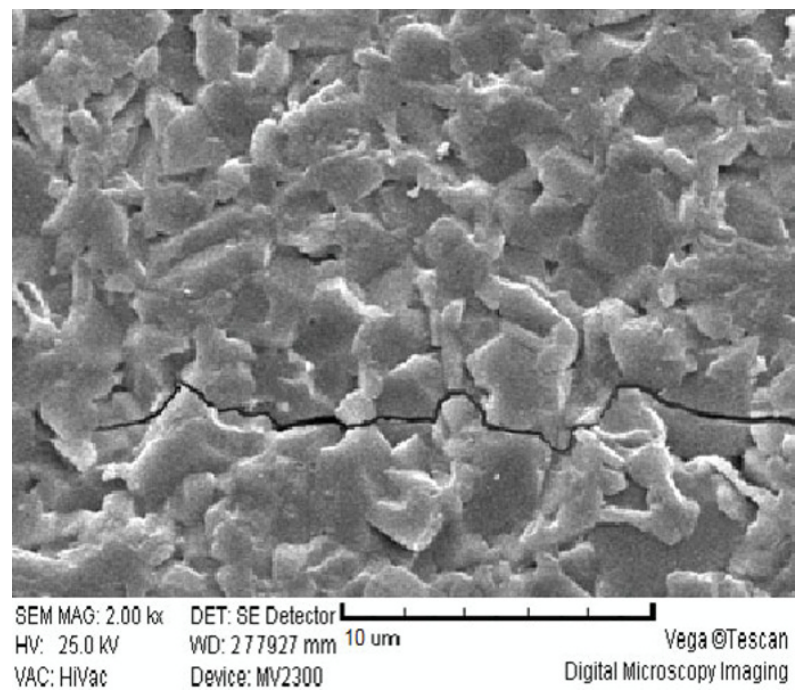

(a)

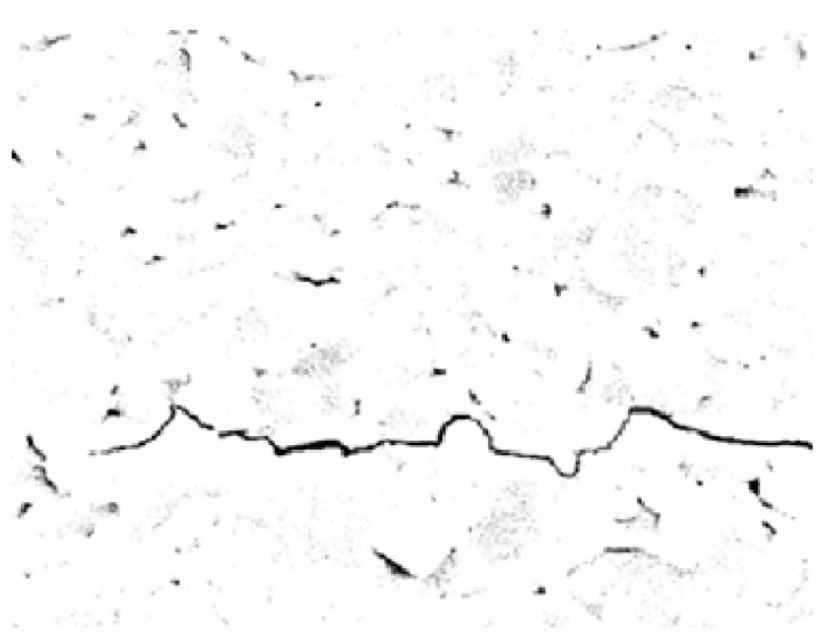

(b)

Fig. 4 (a) Formed crack in $\mathrm{Al}_{2} \mathrm{O}_{3}-7.5 \% \mathrm{SiC}$ specimen; (b) preparation of the crack to be calculated by Image Analyzer Software. 


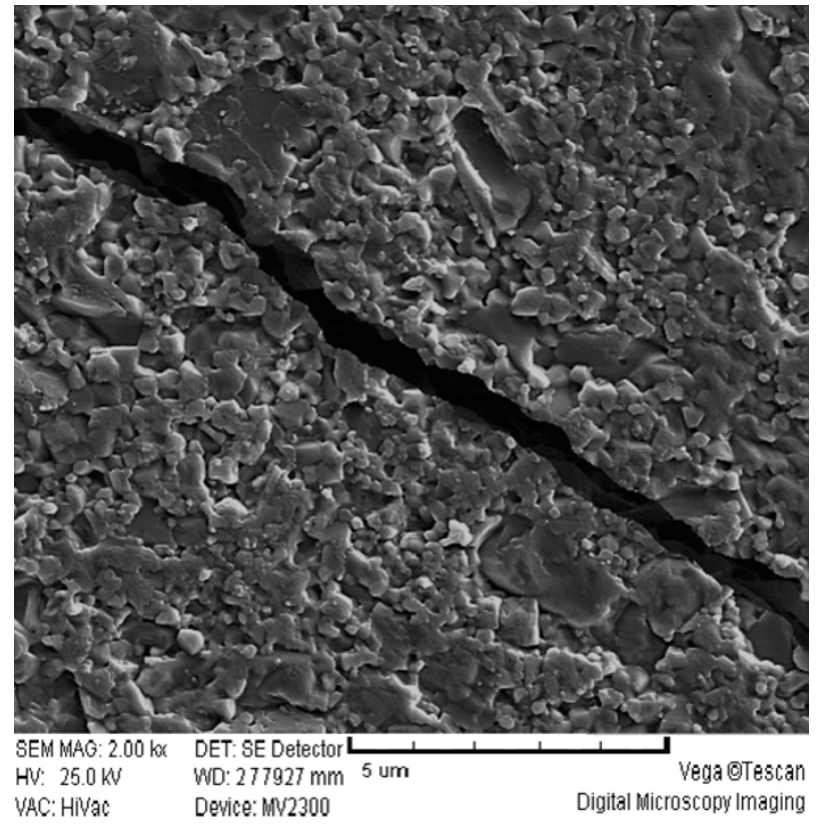

(a)

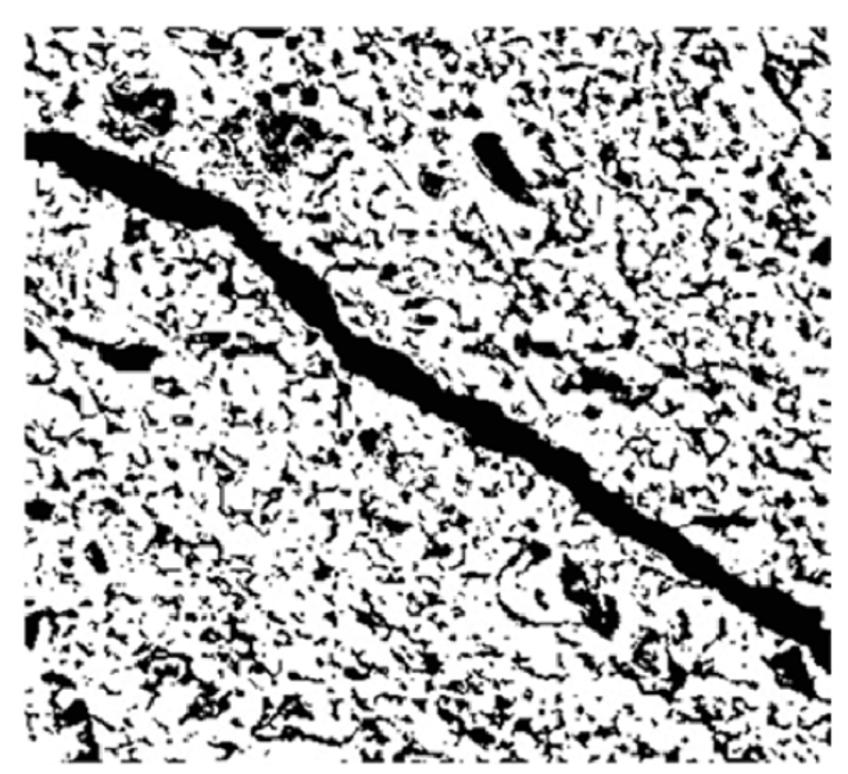

(b)

Fig. 5 (a) Formed crack in $\mathrm{Al}_{2} \mathrm{O}_{3}-15 \% \mathrm{SiC}$ specimen; (b) preparation of the crack to be calculated by Image Analyzer Software.

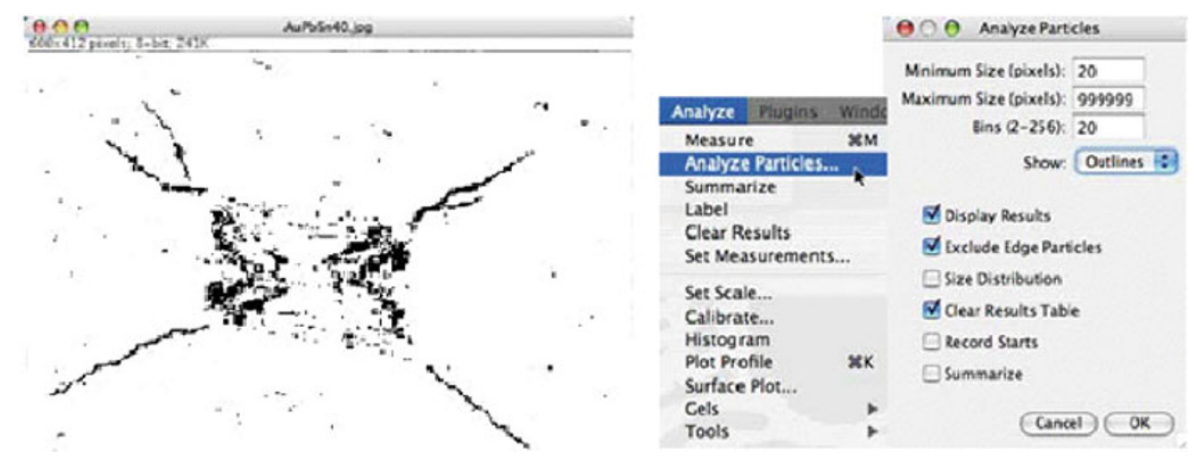

Fig. 6 Separation of cracks by software in order to measure the required values.

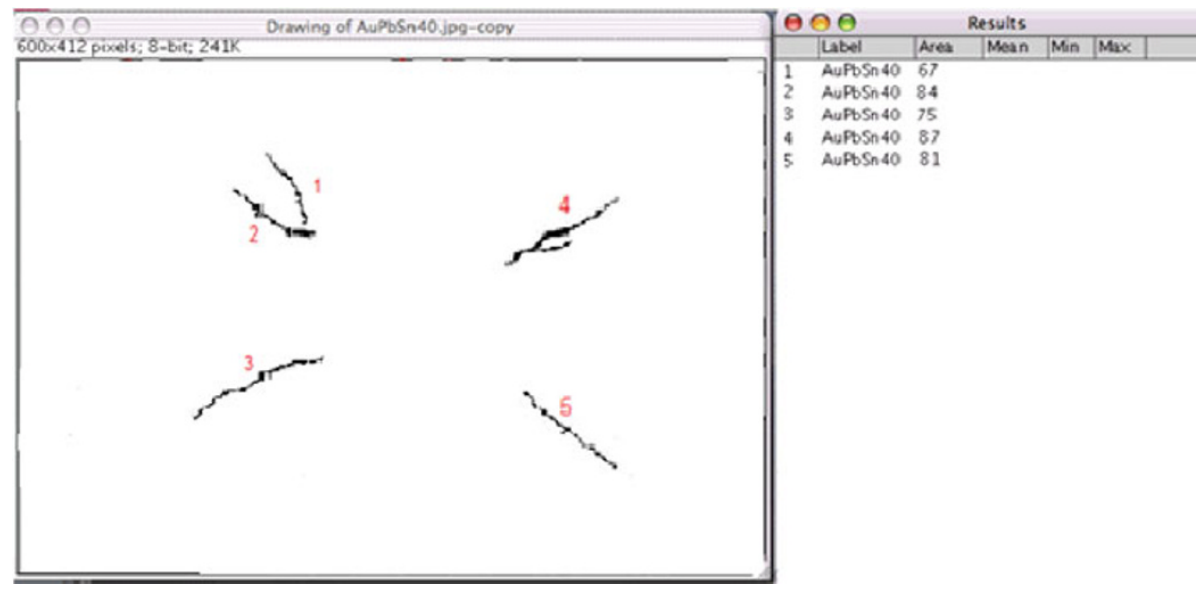

Fig. 7 Calculation the area values of cracks.

It can be discovered that, with analyzing each image of the specimen, the process of calculation will be longer than crack length measurement. But precise result as well as cost saving, which result from reduction in the number of tests for finding straight cracks, make this method reasonable. 


\section{Experimental tests}

The purpose of the following experiment is to make $\mathrm{Al}_{2} \mathrm{O}_{3}-\mathrm{SiC}$ ceramic nanocomposite work pieces by the powder metallurgy method, and evaluate their fracture toughness values. In this investigation, main-phase alumina powder $\left(\gamma-\mathrm{Al}_{2} \mathrm{O}_{3}\right)$ with $99.6 \%$ purity (determined by the X-ray diffraction pattern) was used. Table 2 shows the existing impurities through chemical analysis. The alumina powder had an average grain size of about $5 \mu \mathrm{m}$.

Table 2 Chemical analysis of micronized alumina powder as raw material

\begin{tabular}{cc}
\hline Mixture & Percentage $(\mathrm{wt} \%)$ \\
\hline $\mathrm{Al}_{2} \mathrm{O}_{3}$ & $>99.6$ \\
$\mathrm{Na}_{2} \mathrm{O}$ & $<0.1$ \\
$\mathrm{Fe}_{2} \mathrm{O}_{3}$ & $<0.03$ \\
$\mathrm{SiO}_{2}$ & $<0.05$ \\
$\mathrm{TiO}_{2}$ & $<0.005$ \\
$\mathrm{CaO}$ & $<0.05$ \\
$\mathrm{MgO}$ & $<0.1$ \\
\hline
\end{tabular}

The SiC nanopowder ( $\alpha$-SiC phase) had an average grain size of $80 \mathrm{~nm}$ and purity of $96.5 \%$. Moreover, $\mathrm{MgO}$ powder was obtained through thermal decomposition of ammonium oxalate and magnesium sulfate with particle size less than $100 \mathrm{~nm}$, based on the research by Ahmadzadeh et al. [32]. Table 3 lists the chemical composition of existing impurities in $\mathrm{SiC}$ nanopowder.

Table 3 Chemical composition of existing impurities in primary $\mathrm{SiC}$ nanopowder

\begin{tabular}{cc}
\hline Mixture & Percentage $\left(\mathrm{wt}^{\%} \%\right)$ \\
\hline $\mathrm{C}$ (free) & 0.58 \\
$\mathrm{SiC}$ (free) & 0.22 \\
$\mathrm{Al}$ & 0.03 \\
$\mathrm{O}$ & 3.50 \\
\hline
\end{tabular}

After weighing the raw materials, a suspension of them with isopropanol was prepared and placed in a steel mill chamber with tungsten carbide (WC) walls, which contained 22 beads of tungsten carbide. These materials were mixed in the mill at a speed of $150 \mathrm{rpm}$ (revolutions per minute) for $3 \mathrm{~h}$ until they were homogenized. The resulting slurry was taken out of the mill and placed in a thermal drier at the temperature of $90{ }^{\circ} \mathrm{C}$ for $24 \mathrm{~h} .340 \mathrm{~g}$ of the obtained powder was formed in a press machine at a pressure of about $2 \mathrm{MPa}$ and the holding time of $30 \mathrm{sec}$. The pieces thus obtained were placed in a hot pressing apparatus with graphite mold and argon atmosphere, and were sintered up to the temperature of $1750{ }^{\circ} \mathrm{C}$ for $2 \mathrm{~h}$ and under simultaneous pressure of $30 \mathrm{MPa}$. With the elapse of sintering time, the furnace was turned off and the specimens were allowed to cool naturally to room temperature. These pieces were then cut to $4 \mathrm{~mm} \times$ $3 \mathrm{~mm} \times 45 \mathrm{~mm}$ samples and polished to $1 \mu \mathrm{m}$ to be ready for determining their modulus of elasticity, hardness and fracture toughness.

\section{Evaluation of the results}

\section{1 Modulus of elasticity and hardness}

The relative density of alumina nanocomposite, with the addition of $5 \% \mathrm{SiC}$ and $0-300 \mathrm{ppm} \mathrm{MgO}$, at the sinter temperature of $1750{ }^{\circ} \mathrm{C}$, has been reported at about $93 \%-98 \%$ [33]. In this research, by adding $500 \mathrm{ppm} \mathrm{MgO}$, a relative density of about $99 \%$ was obtained for the compound.

The samples' modulus of elasticity (with four measurements) have been shown in Fig. 8, and the hardness values of the samples (with seven measurements) have been illustrated in Fig. 9, both versus volume fraction (vol\%) of $\mathrm{SiC}$ nanopowder. By observing these figures, it can be seen that the modulus of elasticity and hardness values of the sintered specimens have a rising trend up to $7.5 \mathrm{vol} \%$ of $\mathrm{SiC}$ nanopowder, and then they have diminished afterwards.

Through the examination of Figs. 8 and 9, the average values of Young's modulus and Vickers hardness of the specimens are extracted and listed in Table 4.

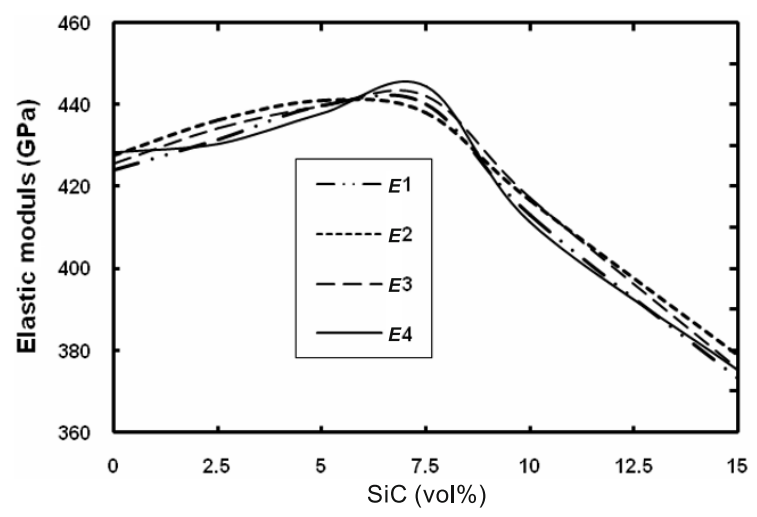

Fig. 8 Young's modulus of the samples. 


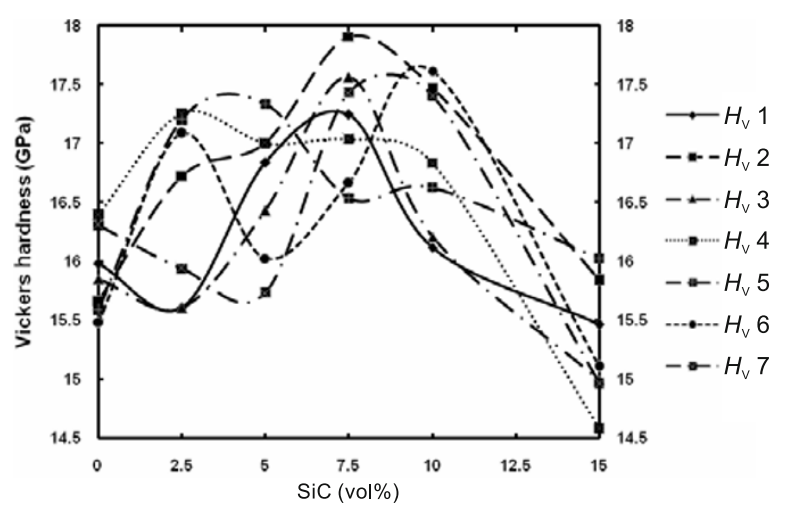

Fig. 9 Vickers hardness of the samples.

Table 4 Average values of Young's modulus and Vickers hardness of the samples

\begin{tabular}{ccc}
\hline Material & $\begin{array}{c}\text { Young's modulus } \\
(\mathrm{GPa})\end{array}$ & $\begin{array}{c}\text { Vickers hardness } \\
(\mathrm{GPa})\end{array}$ \\
\hline $\mathrm{Al}_{2} \mathrm{O}_{3}$ & $426.3 \pm 2$ & $15.89 \pm 0.45$ \\
$\mathrm{Al}_{2} \mathrm{O}_{3}-2.5 \% \mathrm{SiC}$ & $433.1 \pm 3$ & $16.48 \pm 0.82$ \\
$\mathrm{Al}_{2} \mathrm{O}_{3}-5 \% \mathrm{SiC}$ & $439.6 \pm 2$ & $16.62 \pm 0.80$ \\
$\mathrm{Al}_{2} \mathrm{O}_{3}-7.5 \% \mathrm{SiC}$ & $441.2 \pm 3$ & $17.19 \pm 0.68$ \\
$\mathrm{Al}_{2} \mathrm{O}_{3}-10 \% \mathrm{SiC}$ & $414.6 \pm 3$ & $16.89 \pm 0.74$ \\
$\mathrm{Al}_{2} \mathrm{O}_{3}-15 \% \mathrm{SiC}$ & $375.6 \pm 3$ & $15.28 \pm 0.72$ \\
\hline
\end{tabular}

The increase of modulus of elasticity up to $7.5 \mathrm{vol} \%$ of $\mathrm{SiC}$ nanopowder can be attributed to the high modulus of elasticity of silicon carbide relative to that of alumina [34]. Therefore, it is expected that with the increase of silicon carbide, the modulus of elasticity of the nanocomposite increases as well. But with the further increase of silicon carbide portion, the density diminishes, and the formation of porosity leads to the reduction of sound speed in the sample [34], thereby reducing the modulus of elasticity. Also in the results of hardness test performed with $98 \mathrm{~N}$ loading, it seems that with the increase of silicon carbide portion beyond $7.5 \mathrm{vol} \%$, the porosity increases and the density diminishes, thereby reducing the amount of hardness. Conversely, the agglomeration of $\mathrm{SiC}$ nanoparticle increases and their distribution in alumina powder becomes less uniform, thus causing the hardness to drop. Likewise, with the increase of silicon carbide portion, the residual stress arising from thermal expansion difference between $\mathrm{SiC}$ and $\mathrm{Al}_{2} \mathrm{O}_{3}$ increases, until it releases and causes micro-cracks to form in $\mathrm{SiC}$ [35]; as a result, the hardness diminishes.

\section{2 Fracture toughness}

Figures 10, 11 and 12 respectively show the fracture toughness values of various samples obtained by SENB, SEVNB and CNB methods, which have been measured by the four-point flexure model. The specimens have been fabricated and tested with the $a / w$ ratio of about 0.5 (where $a$ is the groove depth and $w$ is the width of the sample). The calculation procedure and accuracy of fracture toughness values obtained from these methods have been thoroughly covered in [1-6] and [36]. Fracture toughness values have been measured for four times in SEVNB and SENB methods, and three times in CNB method.

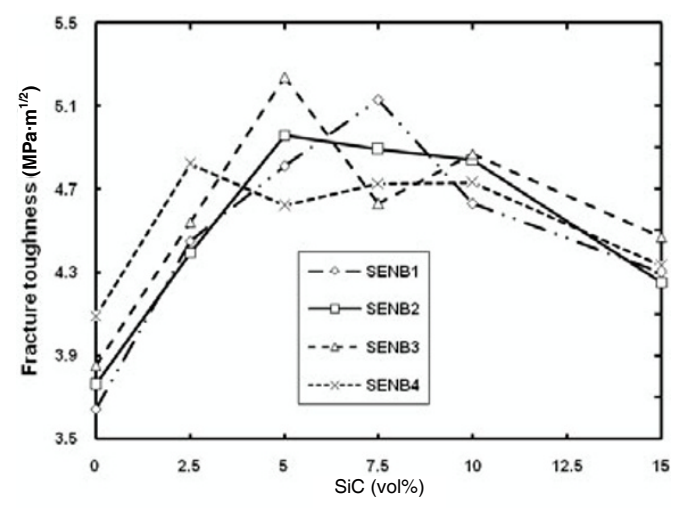

Fig. 10 Fracture toughness values of the samples obtained by SENB method.

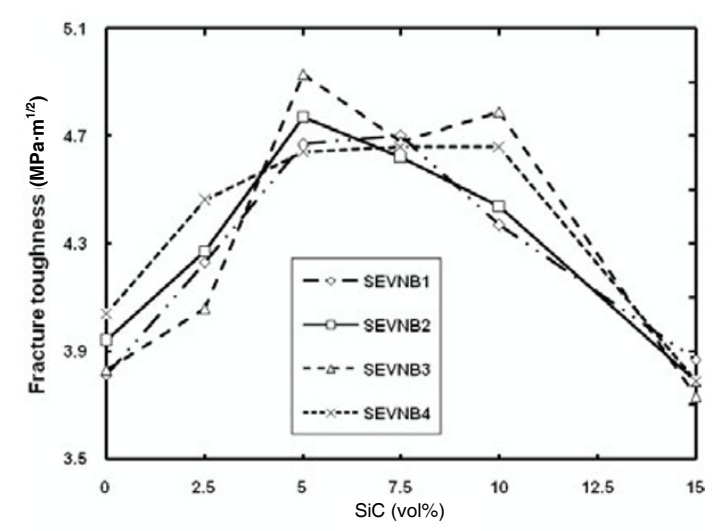

Fig. 11 Fracture toughness values of the samples obtained by SEVNB method.

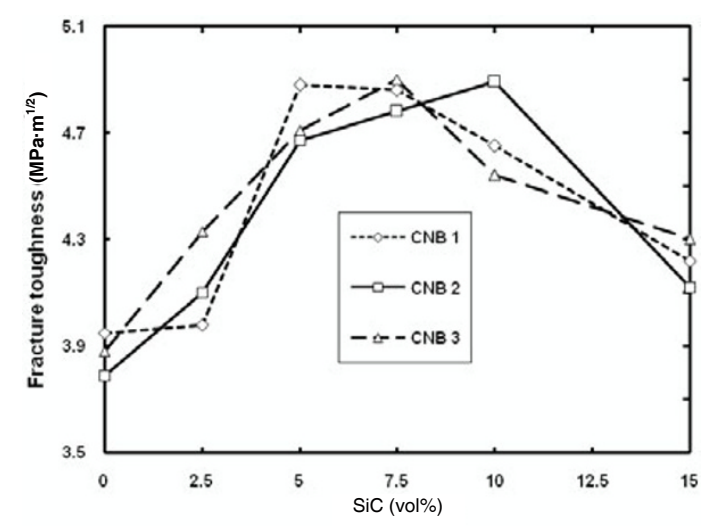

Fig. 12 Fracture toughness values of the samples obtained by CNB method. 
Through the examination of Figs. 10, 11 and 12, fracture toughness values of the specimens are obtained and listed in Table 5 .

\begin{tabular}{|c|c|c|c|}
\hline Material & $\begin{array}{c}\text { SENB } \\
\left(\mathrm{MPa} \cdot \mathrm{m}^{1 / 2}\right)\end{array}$ & $\begin{array}{c}\text { SEVNB } \\
\left(\mathrm{MPa} \cdot \mathrm{m}^{1 / 2}\right)\end{array}$ & $\begin{array}{c}\mathrm{CNB} \\
\left(\mathrm{MPa} \cdot \mathrm{m}^{1 / 2}\right)\end{array}$ \\
\hline $\mathrm{Al}_{2} \mathrm{O}_{3}$ & $3.83 \pm 0.26$ & $3.90 \pm 0.11$ & $3.87 \pm 0.08$ \\
\hline $\mathrm{Al}_{2} \mathrm{O}_{3}-2.5 \% \mathrm{SiC}$ & $4.55 \pm 0.24$ & $4.25 \pm 0.21$ & $4.14 \pm 0.175$ \\
\hline $\mathrm{Al}_{2} \mathrm{O}_{3}-5 \% \mathrm{SiC}$ & $4.90 \pm 0.30$ & $4.75 \pm 0.18$ & $4.75 \pm 0.11$ \\
\hline $\mathrm{Al}_{2} \mathrm{O}_{3}-7.5 \% \mathrm{SiC}$ & $4.84 \pm 0.27$ & $4.66 \pm 0.04$ & $4.85 \pm 0.06$ \\
\hline $\mathrm{Al}_{2} \mathrm{O}_{3}-10 \% \mathrm{SiC}$ & $4.76 \pm 0.12$ & $4.56 \pm 0.23$ & $4.70 \pm 0.018$ \\
\hline $\mathrm{Al}_{2} \mathrm{O}_{3}-15 \% \mathrm{SiC}$ & $4.33 \pm 0.14$ & $3.80 \pm 0.07$ & $4.22 \pm 0.09$ \\
\hline
\end{tabular}

\section{3 Calculation of the semi-empirical coefficient in Eq. (7)}

Now, having the exact values of the specimens' fracture toughness, Young's modulus and Vickers hardness, the semi-empirical coefficients of the equation are determined by using the areas and thicknesses of micro-crack tracks. A $150 \mathrm{~N}$ force was applied to the samples for $15 \mathrm{sec}$ in order to calculate the values of fracture toughness through the indentation test, using the thickness and area of micro-crack tracks. Figures 13-17 illustrate the effect

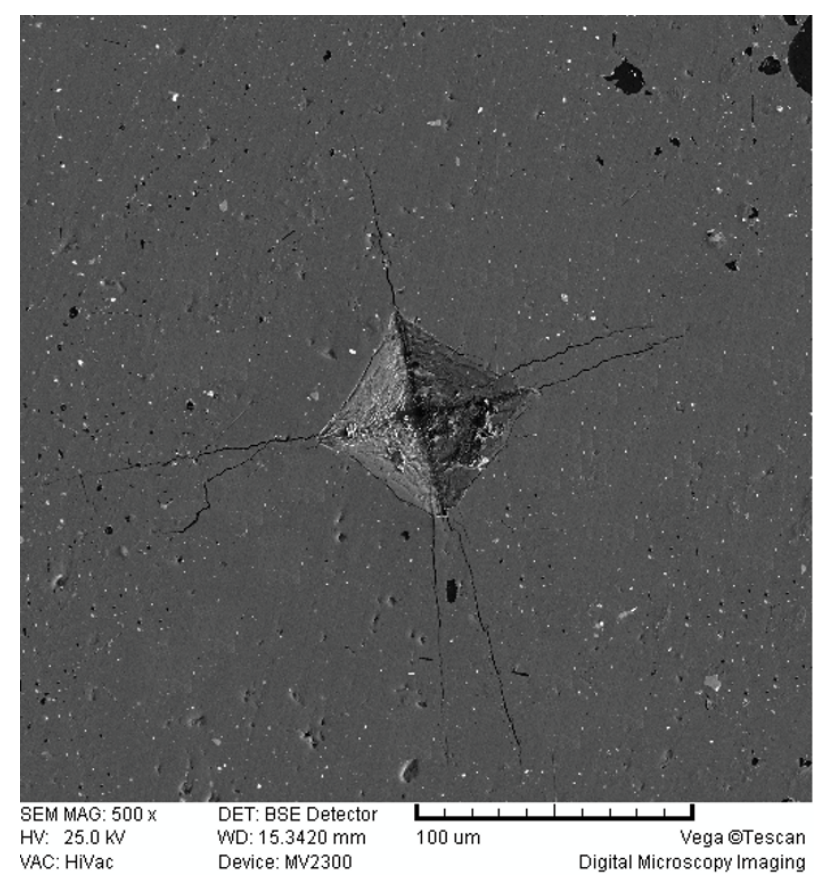

Fig. 13 SEM microstructure image of Vickers hardness test in a sample without the $\mathrm{SiC}$ nanopowder additive. of Vickers test on some specimens. The shown SEM images indicate the existence of irregular cracks around the indented section.

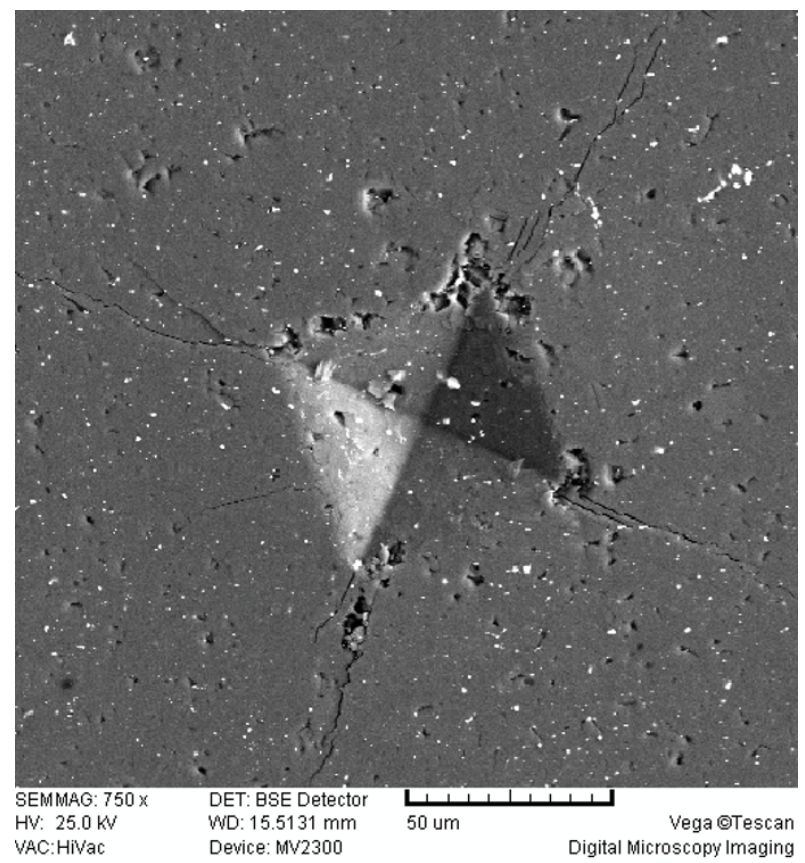

Fig. 14 SEM microstructure image of Vickers hardness test in a sample with $2.5 \mathrm{vol} \%$ of $\mathrm{SiC}$ nanopowder additive.

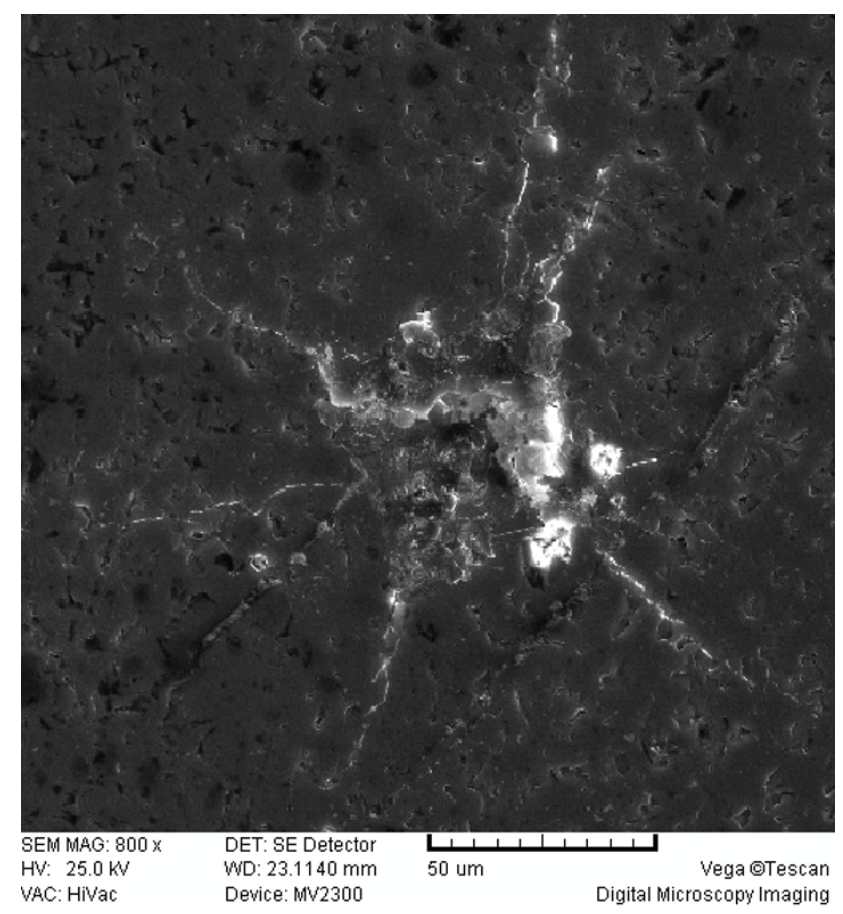

Fig. 15 SEM microstructure image of Vickers hardness test in a sample with $7.5 \mathrm{vol} \%$ of $\mathrm{SiC}$ nanopowder additive. 


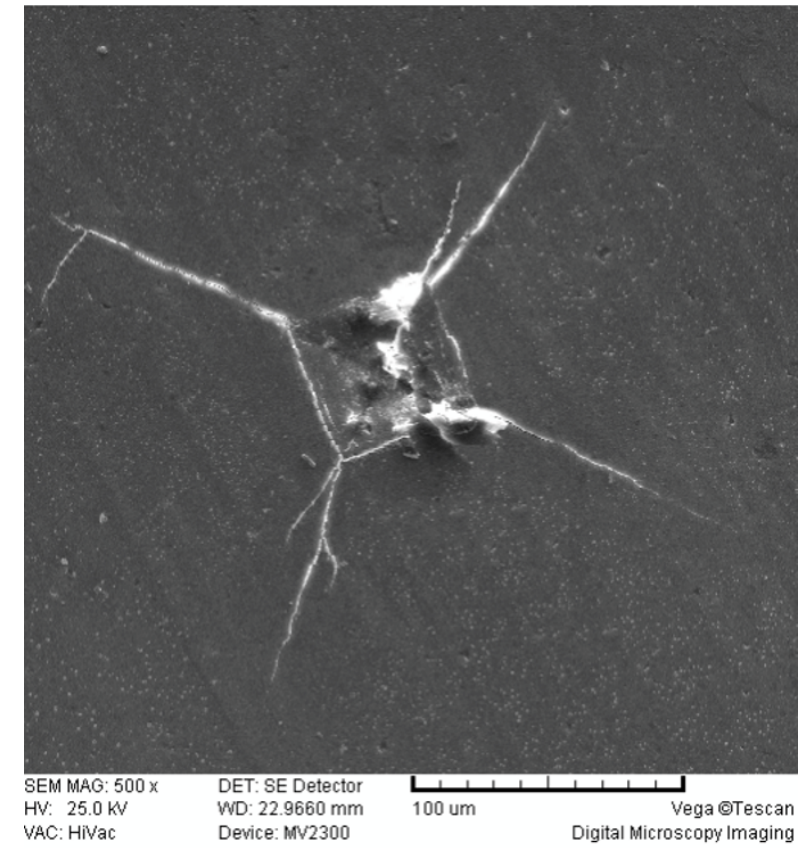

Fig. 16 SEM microstructure image of Vickers hardness test in a sample with $10 \mathrm{vol} \%$ of $\mathrm{SiC}$ nanopowder additive.

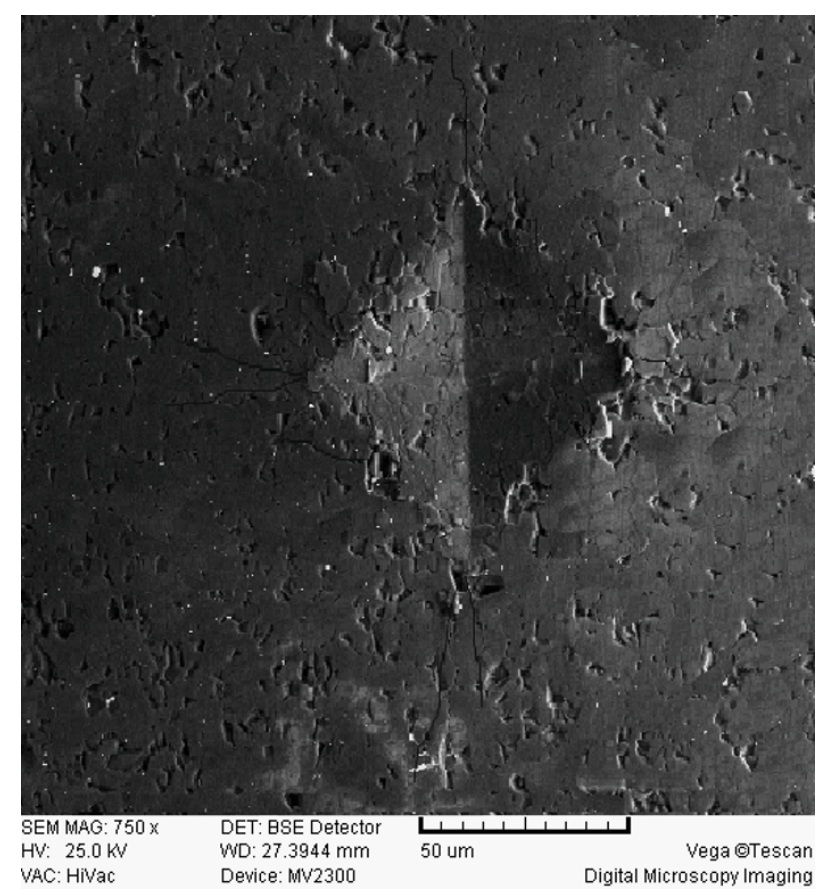

Fig. 17 SEM microstructure image of Vickers hardness test in a sample with $15 \mathrm{vol} \%$ of $\mathrm{SiC}$ nanopowder additive.

If the loading magnitude reaches $196 \mathrm{~N}$, the chipping phenomenon will occur in the specimens. Figures 18 and 19 show the fracture toughness test with $196 \mathrm{~N}$ and $220 \mathrm{~N}$ loads in $\mathrm{Al}_{2} \mathrm{O}_{3}-7.5 \% \mathrm{SiC}$ and $\mathrm{Al}_{2} \mathrm{O}_{3}-5 \% \mathrm{SiC}$ test specimens, respectively.

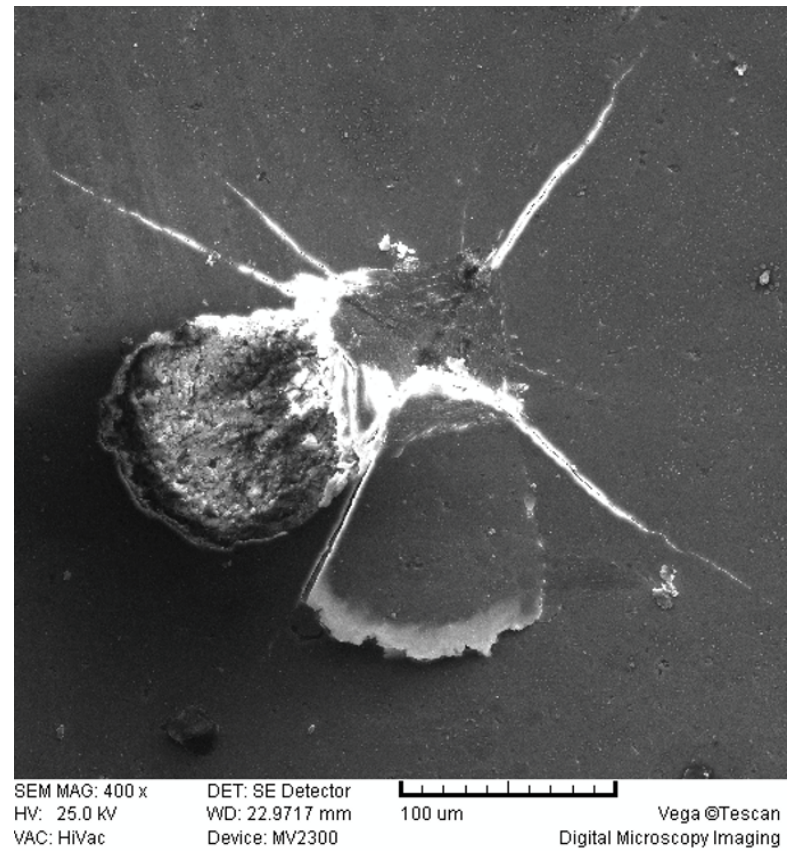

Fig. 18 Example of fracture toughness test in a sample with 7.5 vol\% of $\mathrm{SiC}$ nanopowder using a $196 \mathrm{~N}$ load.

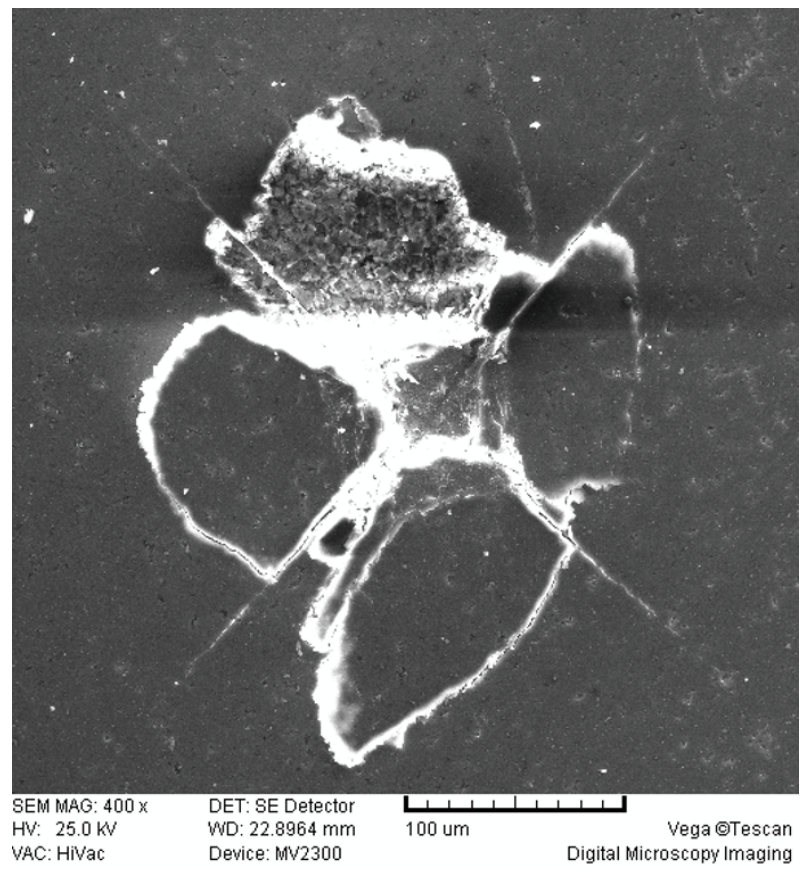

Fig. 19 Example of fracture toughness test in a sample with 5 vol\% of $\mathrm{SiC}$ nanopowder using a $220 \mathrm{~N}$ load.

Figure 20 shows micro-crack thicknesses in micrometer $(\mu \mathrm{m})$, which have been randomly measured for seven times at crack locations on the samples by means of Image Analyzer Software. 


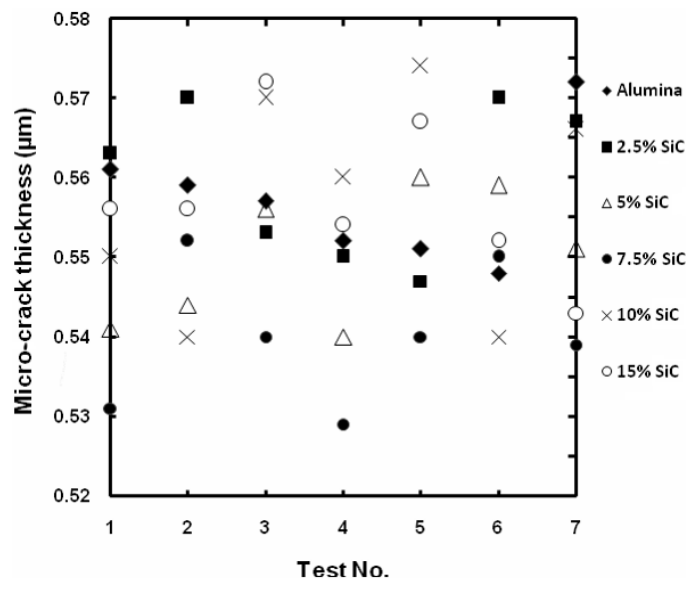

Fig. 20 Micro-crack thickness in each sample.

As Fig. 20 indicates, at each measurement, different micro-crack thicknesses have been obtained, which is justified based on the fact that when we get to the indented region closer, the thickness of micro-cracks increases.

The total areas of micro-crack trails left in samples are estimated in seven trials by means of the mentioned software. These values for each sample can be seen in Fig. 21. These areas have been obtained for six different samples.

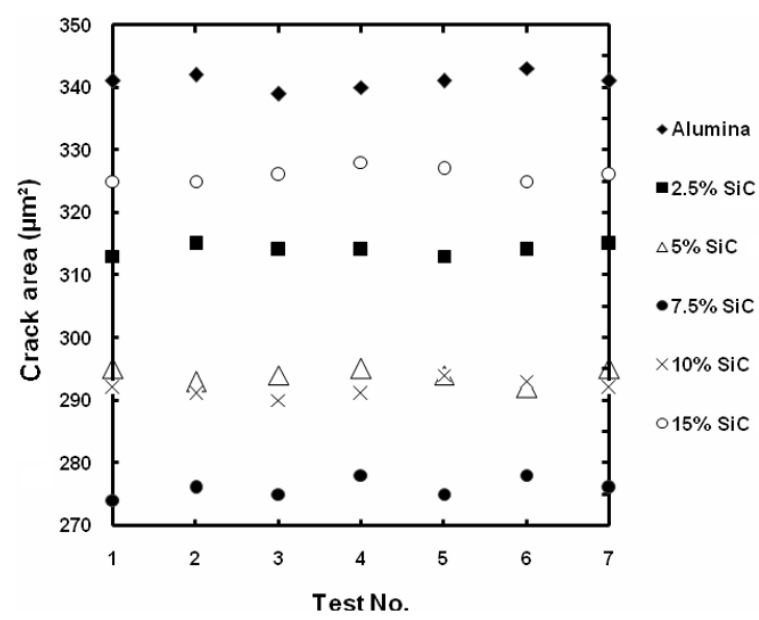

Fig. 21 Micro-crack area in each sample.

As is obvious from Fig. 21, the measured areas are very close to each other. Each measurement includes the whole area of the micro-crack, and indicates a very small error obtained through the software. The average values of these areas can be seen in Table 6 .

Having all the right-hand-side values of Eq. (7), the correction coefficient $\zeta$ is evaluated. These values are determined by inserting all the obtained data into the right side of this relation. Figures $22-24$ show $\zeta$ with respect to variables of track area and thickness of the micro-cracks in different samples. Since the main indicator of the semi-empirical coefficient of Eq. (7) lies in the changes of micro-crack areas and thicknesses, only the changes of these values have been considered as the main variables, and to reduce the computational load, the average values of other parameters of Eq. (7) have been used in determining $\zeta$.

Table 6 Average areas of micro-cracks in the samples

\begin{tabular}{cc}
\hline Material & Average area $\left(\mu \mathrm{m}^{2}\right)$ \\
\hline $\mathrm{Al}_{2} \mathrm{O}_{3}$ & 341 \\
$\mathrm{Al}_{2} \mathrm{O}_{3}-2.5 \% \mathrm{SiC}$ & 314 \\
$\mathrm{Al}_{2} \mathrm{O}_{3}-5 \% \mathrm{SiC}$ & 294 \\
$\mathrm{Al}_{2} \mathrm{O}_{3}-7.5 \% \mathrm{SiC}$ & 276 \\
$\mathrm{Al}_{2} \mathrm{O}_{3}-10 \% \mathrm{SiC}$ & 292 \\
$\mathrm{Al}_{2} \mathrm{O}_{3}-15 \% \mathrm{SiC}$ & 326 \\
\hline
\end{tabular}

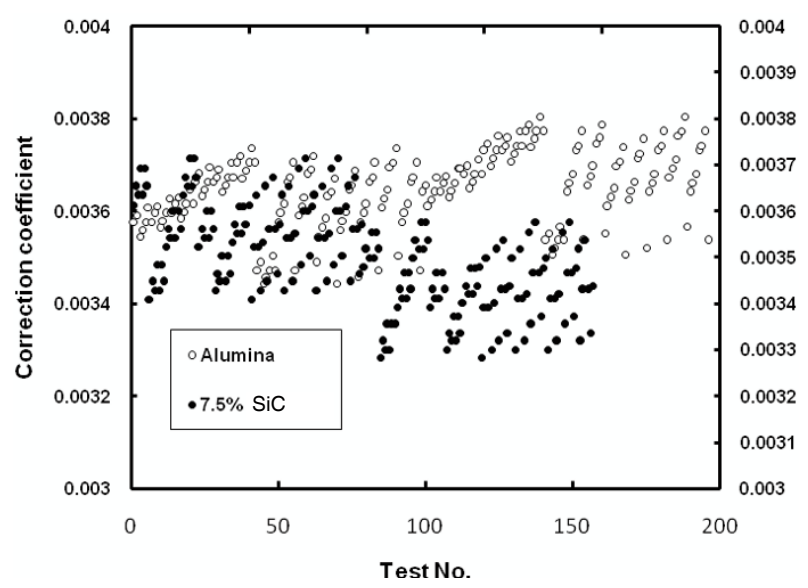

Fig. 22 Correction coefficients for the variables of micro-crack area and thickness measured in $\mathrm{Al}_{2} \mathrm{O}_{3}$ and $\mathrm{Al}_{2} \mathrm{O}_{3}-7.5 \% \mathrm{SiC}$ samples.

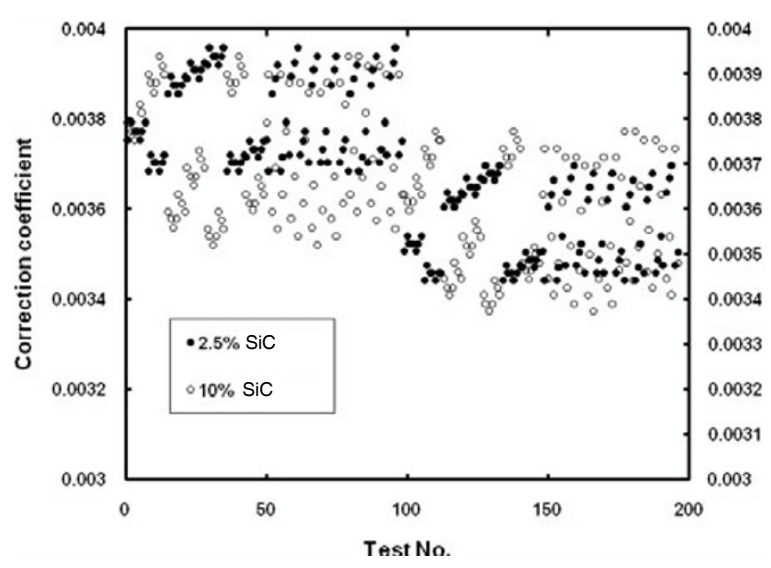

Fig. 23 Correction coefficients for the variables of micro-crack area and thickness measured in $\mathrm{Al}_{2} \mathrm{O}_{3}-2.5 \% \mathrm{SiC}$ and $\mathrm{Al}_{2} \mathrm{O}_{3}-10 \% \mathrm{SiC}$ samples. 


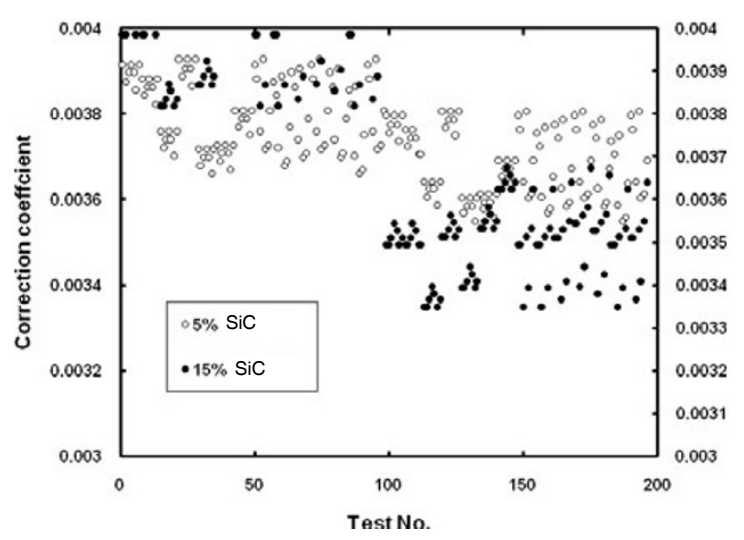

Fig. 24 Correction coefficients for the variables of micro-crack area and thickness measured in $\mathrm{Al}_{2} \mathrm{O}_{3}-5 \% \mathrm{SiC}$ and $\mathrm{Al}_{2} \mathrm{O}_{3}-15 \% \mathrm{SiC}$ samples.

By examining Figs. 22-24, the average correction coefficient in Eq. (6) can be considered equal to $0.00366 \pm 0.0003$. Thus, Eq. (6) can be rewritten as

$$
K_{\mathrm{IC}}=0.00366\left(\frac{E}{H_{\mathrm{v}}}\right)^{\frac{1}{2}} t^{\frac{3}{2}} \frac{P}{A^{\frac{3}{2}}}
$$

\section{Discussion and review of the results}

Figure 25 illustrates the comparison between fracture toughness values obtained through equations 1-10 expressed in Table 1 and obtained by Eq. (8), in which the micro-crack area has been used instead of the length parameter, and the average values of common SENB and SEVNB methods are compared as well. The diagram values corresponding to Nos. $1-10$ on the horizontal axis indicate fracture toughness values based on the cited relations in Table 1. Data corresponding to No. 11 on the horizontal axis are fracture toughness values according to Eq. (8), and also the values listed in Table 5 for SENB and SEVNB methods are given in the end portion of the horizontal axis for different percentages of $\mathrm{SiC}$ nanopowder.

If a comparison is made between fracture toughness values obtained from Eq. (8) and from other relations for determination of fracture toughness by Vickers test, it can be seen that although the values obtained from the mentioned equation depend more or less on material structure, brittleness, Vickers hardness, Young's modulus, and other mechanical properties and conditions, there is considerable savings associated with the use of this approach, because we no longer need repeated experiments in order to produce standard and regular cracks.

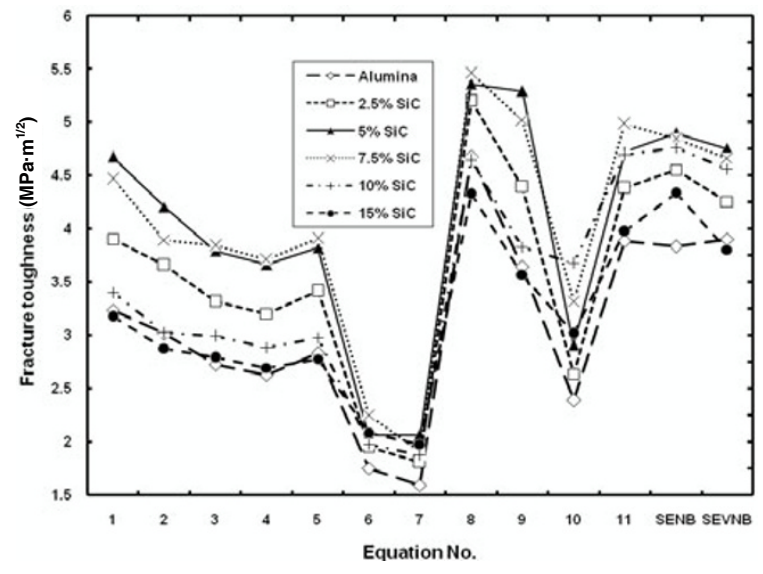

Fig. 25 Comparison between fracture toughness values obtained by all the cited relations.

Observing the plots in Fig. 25, it can be concluded that the obtained values corresponding to Nos. 6 and 7 on the horizontal axis (equations 6 and 7 from Table 1) have considerable differences with the results of other equations. The reason could be that in these two equations, the crack length parameter ( $c$ in Fig. 1) has been expressed as squared. In fact, they are the only two equations in Table 1 whose crack lengths have been expressed as squared values. Since the experiments of this research lead to the creation of irregular cracks, it can be stated that the most influential parameters in the determination of fracture toughness are related to crack tracks (length and/or area of tracks). Because these parameters have less effect in these two equations, the error due to their use is higher with regards to the overall structural change of the existing cracks in the experiments of this research. In addition, it should be noted that the findings of other previous researchers [15-29] have always been accompanied with great differences (in some cases up to $30 \%$ ) compared to those of other common methods, indicating a natural difference between them.

Figure 26 illustrates the difference of fracture toughness results (in percent) between those obtained by available equations in Table 1, the output values of SENB and SEVNB methods, and the output values of Eq. (8). In the figure, Nos. 1-10 on the horizontal axis show the equations $1-10$ in Table 1 , and the vertical axis shows the values of difference percent.

From Fig. 26, it can be realized that, the difference between the results of SENB and SEVNB methods and Eq. (8) is less than $10 \%$. This small difference expresses the high accuracy of Eq. (8). This difference for most of other equations is between $10 \%$ and $30 \%$, 
and in some cases even close to $40 \%$.

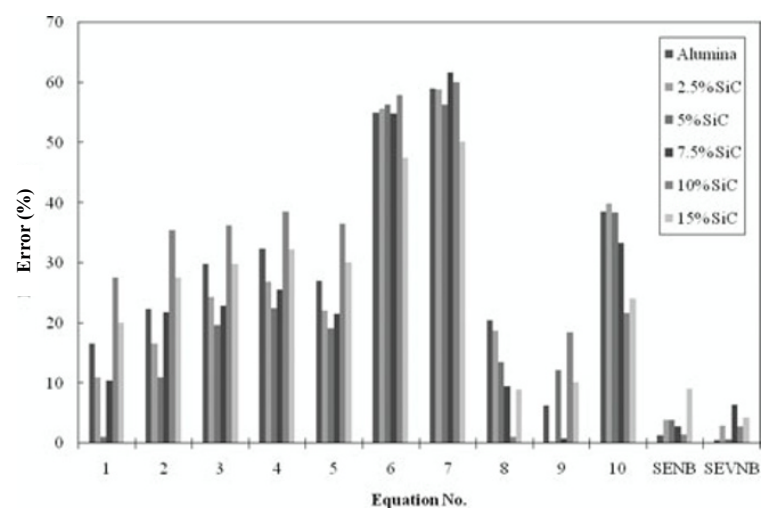

Fig. 26 Error values (in percent) of the fracture toughness equations results from Table 1, and SENB and SEVNB methods, versus Eq. (8).

The fracture toughness of alumina nanocomposites with $\mathrm{SiC}$ additive has been reported in the range of 3-5.5 $\mathrm{MPa} \cdot \mathrm{m}^{1 / 2}$ [37]. The results of this research are also within this range and have acceptable agreement with the results of common and exact SEVNB and SENB methods outlined in Fig. 25. As observed in this figure, the highest calculated fracture toughness value is in the nanocomposite of $\mathrm{Al}_{2} \mathrm{O}_{3}-7.5 \% \mathrm{SiC}$, and in some cases, in $\mathrm{Al}_{2} \mathrm{O}_{3}-5 \% \mathrm{SiC}$. With the increase of $\mathrm{SiC}$ quantity, the agglomeration of $\mathrm{SiC}$ nanoparticles increases and their distribution within the alumina becomes less uniform [34]; on the other hand, the residual stress arising from thermal expansion difference between $\mathrm{SiC}$ and $\mathrm{Al}_{2} \mathrm{O}_{3}$ increases, and the release of this stress weakens the grain boundaries [35]. As a result, with the reduction of strength against crack formation, fracture toughness diminishes.

It should be noted that due to the branching of cracks around the indented region of every sample, each side of the sample exhibits increased number of $c$. This increase in the number of $c$, which is accompanied with different lengths, certainly impacts the boundary limit of $c / a$ ratio. By averaging the number of large and small crack lengths formed on all the four sides of the indentation, $n c$ crack lengths can be assumed around the specimen indentation. In fact, for irregular cracks, the nc/a ratio should always be considered in the evaluation of the equation's performance range ( $n$ denotes an estimation of the number of cracks on each side of the indented region). If $n \leqslant 7, c_{\max }=1.4 n$ and $n c / a \geqslant 20$, the use of Eq. (8) will be allowed, because the results of this equation are closer to the results of half-penny model and SEVNB and SENB methods.

In general, it is assumed that in the determination of fracture toughness of materials with low toughness, Eq. (8) can be used. The physical justification for this presumption is that, by experience, Vickers test's results in highly brittle materials correlate with the number of cracks around the indented zone. It should always be noted that this equation has been derived based on the relations that are true for highly brittle materials. It has been proven experimentally that, in general, high brittleness will increase the extent of cracks produced in Vickers test [15]. Moreover, to produce radial cracks in these types of materials, it is necessary to increase the number of tests and to change the amount of loading in a trial and error fashion in order to achieve the desired specimen. This, in itself, shows the vast range of application of Eq. (8) to highly brittle materials. Another important point is the error induced in facture toughness values with the change of crack propagation in the depth of specimen. Since it is not possible to accurately measure crack depths, and the increase of micro-crack propagation along the sample's depth has a direct relationship with the increase of micro-crack track area on the surface, and also this surface micro-crack area impacts the output of the fracture toughness (Eq. (8)), the indirect influence of micro-crack propagation along the depth can somehow be witnessed in the areas of surface micro-crack tracks that emerge in the equation. Besides, cracks normally don't propagate in a straight line, and they are usually accompanied by small deviations and zigzag movements. Figures 27 and 28 show these deviations along the longitudinal propagation in $\mathrm{Al}_{2} \mathrm{O}_{3}-5 \% \mathrm{SiC}$ and $\mathrm{Al}_{2} \mathrm{O}_{3}-10 \% \mathrm{SiC}$ samples, respectively. These deviations also lead to error when using the previous relations, and confirm the accuracy of the obtained formulation in this article.

The effectiveness and accuracy of Eq. (8) in determining fracture toughness values become more pronounced as we test more brittle materials, and by implementing the needed modifications in the empirical coefficient of the equation, its accuracy is enhanced.

Figure 29 compares the fracture toughness values of the samples obtained by Eq. (8) with those calculated through CNB method and listed in Table 5. Since CNB method is one of the most accurate methods for the determination of material toughness, the closeness of Eq. (8)'s results to the results of CNB method is indicative of the accuracy of the equation. 


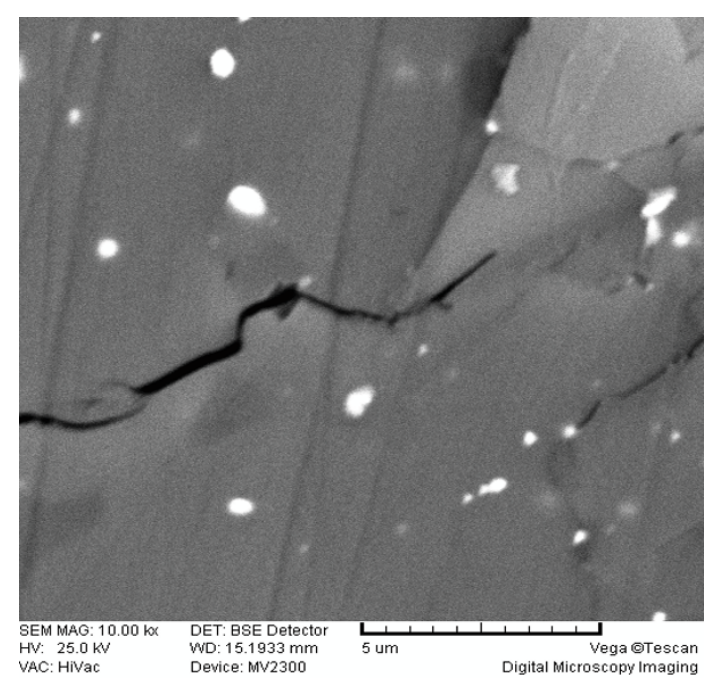

Fig. 27 Zigzag crack tracks along the longitudinal propagation in $\mathrm{Al}_{2} \mathrm{O}_{3}-5 \% \mathrm{SiC}$ sample.

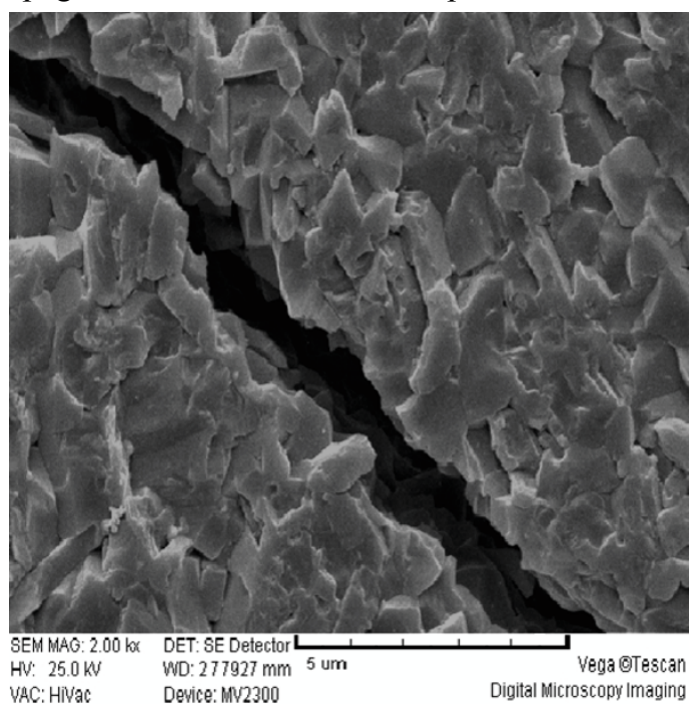

Fig. 28 Zigzag crack tracks along the longitudinal propagation in $\mathrm{Al}_{2} \mathrm{O}_{3}-10 \% \mathrm{SiC}$ sample.

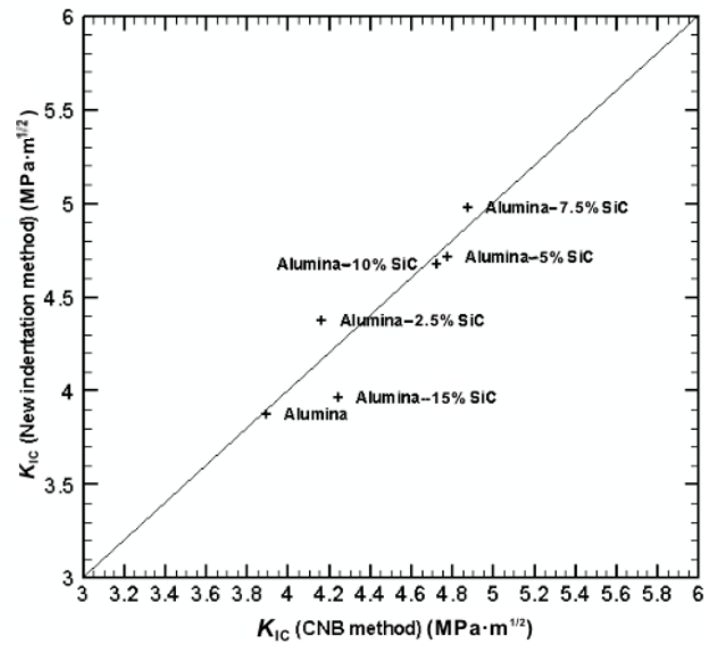

Fig. 29 Comparison of the fracture toughness values between results obtained by Eq. (8) and those by CNB method.

\section{Conclusions}

The important objective of this research is to devise a method that, in addition to improving the accuracy of final results, substantially reduces the needs to qualitatively develop indentation-fracture-toughness equations and to perform costly trial-and-error type experimental procedures to achieve straight cracks. Thus, the following research findings can be cited:

(1) For the determination of fracture toughness, indentation test in brittle materials is only applicable for the sake of comparison with other common and exact approaches, and the values solely obtained by this method cannot be considered sufficient for design purpose.

(2) The fracture toughness values obtained by the derived equation have acceptable accuracy compared to the results of other relations. Although the obtained equation makes the calculation procedure more complex and requires the use of a software program, it cuts down the experiment-related expense.

(3) The lack of chipping phenomenon in samples is the only main condition for the application of the mentioned equation. Also, the least amount of brittleness will be established in specimens, if $n \leqslant 7$, $c_{\max }=1.4 n$ and $n c / a \geqslant 20$, where $n$ denotes an estimation of the number of cracks on each side of the indented region.

(4) The amount of error arising from the use of obtained equation in different ceramic specimens, relative to SEVNB, SENB and CNB methods, has been less than $10 \%$, which considering the standards of toughness test by the indentation method makes the obtained equation highly accurate.

(5) With the repeating of the procedure in this investigation, the range and effectiveness of the obtained equation can be extended by changing the value of its empirical coefficients in both models.

Open Access: This article is distributed under the terms of the Creative Commons Attribution Noncommercial License which permits any noncommercial use, distribution, and reproduction in any medium, provided the original author(s) and source are credited.

\section{References}

[1] Wang MD, Shaw L. Effects of the powder 
manufacturing method on microstructure and wear performance of plasma sprayed alumina-titania coatings. Surf Coat Technol 2007, 202: 34-44.

[2] Vullo P, Davis MJ. Comparative study of micro-indentation and Chevron notch fracture toughness measurements of silicate and phosphate glasses. J Non-Cryst Solids 2004, 349: 180-184.

[3] Mukhopadhyay AK, Datta SK, Chakraborty D. Fracture toughness structural ceramic. Ceram Int 1999, 25: 447-454.

[4] Tsukuma K, Shimada M. Strength, fracture toughness and Vickers hardness of $\mathrm{CeO}_{2}$-stabilized tetragonal $\mathrm{ZrO}_{2}$ polycrystals (Ce-TZP). J Mater Sci 1985, 20: 1178-1184.

[5] Nose T, Fujii T. Evaluation of fracture toughness for ceramic materials by a single-edge-precracked-beam method. J Am Ceram Soc 1988, 71: 328-333.

[6] Miyazaki H, Hyuga H, Hirao K, et al. Comparison of fracture resistance as measured by the indentation fracture method and fracture toughness determined by the single-edge-precracked beam technique using silicon nitrides with different microstructures. $J$ Eur Ceram Soc 2007, 27: 2347-2354.

[7] Wang J, Zheng XH, Stevens R. Fabrication and microstructure-mechanical property relationships in Ce-TZPs. J Mater Sci 1992, 27: 5348-5356.

[8] Rice RW. Microstructural dependence of fracture energy and toughness of ceramics and ceramic composites versus that of their tensile strengths at $22{ }^{\circ} \mathrm{C}$. J Mater Sci 1996, 31: 4503-4519.

[9] Kruzic JJ, Kim DK, Koester KJ, et al. Indentation techniques for evaluating the fracture toughness of biomaterials and hard tissues. $J$ Mech Behav Biomed 2009, 2: 384-395.

[10] Sakharova NA, Fernandes JV, Antunes JM, et al. Comparison between Berkovich, Vickers and conical indentation tests: A three-dimensional numerical simulation study. Int J Solids Struct 2009, 46: 1095-1104.

[11] Li M, Chen WM, Liang NG, et al. A numerical study of indentation using indenters of different geometry. J Mater Res 2004, 19: 73-78.

[12] Palmqvist S. Indentation hardness and fracture toughness in single crystal. Jernkontorets Ann 1957, 141: 300-306.

[13] Mullins LP, Bruzzi MS, McHugh PE. Measurement of the microstructural fracture toughness of cortical bone using indentation fracture. J Biomech 2007, 40: 3285-3288.

[14] Palmqvist S. Energy causing cracks at corners of Vickers indentations as measure of toughness of hard metals. Archiv fuer das Eisenhuettenwes 1962, 33:
629-634.

[15] Anstis GR, Chantikul P, Lawn BR, et al. A critical evaluation of indentation techniques for measuring fracture toughness: I, Direct crack measurements. J Am Ceram Soc 1981, 64: 533-538.

[16] Ponton CB, Rawlings RD. Vickers indentation fracture toughness test Part 1: Review of literature and formulation of standardized indentation toughness equations. Mater Sci Tech 1989, 5: 865-872.

[17] Ponton CB, Rawlings RD. Vickers indentation fracture toughness test Part 2: Application and critical evaluation of standardized indentation toughness equations. Mater Sci Tech 1989, 5: 961-976.

[18] Bamzai KK, Kotru PN, Wanklyn BM. Fracture mechanics, crack propagation and microhardness studies on flux grown $\mathrm{ErAlO}_{3}$ single crystals. J Mater Sci Technol 2000, 16: 405-410.

[19] Bhat DG. Comment on "Elastic/plastic indentation damage in ceramics: The median/radial crack system". J Am Ceram Soc 1981, 64: C-165-C-166.

[20] Bhat M, Kaur B, Kumar R, et al. Effect of ion irradiation on dielectric and mechanical characteristics of $\mathrm{ErFeO}_{3}$ single crystals. Nucl Instrum Meth B 2005, 234: 494-508.

[21] Dub SN, Maistrenko AL. Reliability of ceramics fracture toughness measurements by indentation. In Fracture Mechanics of Ceramics. Brandt RC, Hasselman DPH, Munz D, et al. Eds. New York: Plenum Press, 1992, 10: 109-118.

[22] Glandus JC, Rouxel T, Tai Q. Study of the Y-TZP toughness by an indentation method. Ceram Int 1991, 17: 129-135.

[23] Niihara K, Morena R, Hasselman DPH. Evaluation of $K_{\mathrm{IC}}$ of brittle solids by the indentation method with low crack-to-indent ratios. J Mater Sci Lett 1982, 1: 13-16.

[24] Shetty DK, Wright IG, Mincer PN, et al. Indentation fracture of WC-Co cermets. J Mater Sci 1985, 20: 1873-1882.

[25] Japanese Standards Association. J IS R-1607. Testing method for fracture toughness of high performance ceramics. 1990.

[26] Evans AG, Charles EA. Fracture toughness determinations by indentation. J Am Ceram Soc 1976, 59: 371-372.

[27] Evans AG. Fracture toughness: The role of indentation techniques. In Fracture Mechanics Applied to Brittle Materials. Freiman SW, Ed. ASTM International, 1979: 112-135.

[28] Lawn BR, Evans AG, Marshall DB. Elastic/plastic 
indentation damage in ceramics: The median/radial crack system. J Am Ceram Soc 1980, 63: 574-581.

[29] Lawn BR, Fuller ER. Equilibrium penny-like cracks in indentation fracture. $J$ Mater Sci 1975, 10: 2016-2024.

[30] ASTM International. ASTM C1327-08. Standard test method for Vickers indentation hardness of advanced ceramics.

[31] ASTM International. ASTM C769-98. Standard test method for sonic velocity in manufactured carbon and graphite materials for use in obtaining an approximate Young's modulus.

[32] Ahmadzadeh M, Baharvandi HR, Abdizadeh H, et al. Synthesis of nano-size $\mathrm{MgO}$ powder by chemical deposition of low cost raw materials. Int J Mod Phys B 2008, 22: 3185-3192.
[33] Jeong Y K, Nihara K. Microstructure and properties of alumina-silicon carbide nanocomposite fabricate by pressurelless sintering and post hot-isostatic pressing. Trans Nonferrous Met Soc China 2011, 21: s1-s6.

[34] Anya CC, Roberts SG. Pressureless sintering and elastic constants of $\mathrm{Al}_{2} \mathrm{O}_{3}-\mathrm{SiC}$ nanocomposites. J Eur Ceram Soc 1997, 17: 565-573.

[35] Sternitzke M. Structural ceramic nanocomposites. J Eur Ceram Soc 1997, 17: 1061-1082.

[36] Gogotsi GA. Fracture toughness of ceramics and ceramic composites. Ceram Int 2003, 29: 777-784.

[37] Anya CC, Roberts SG. Indentation fracture toughness and surface faw analysis of sintered alumina/SiC nanocomposites. J Eur Ceram Soc 1996, 16: 1107-1114. 